Article

\title{
Short-Term Cumulative Exposure to Ambient Traffic-Related Black Carbon and Blood Pressure: MMDA Traffic Enforcers' Health Study
}

\author{
Zypher Jude G. Regencia ${ }^{1,2}$, Godofreda V. Dalmacion ${ }^{1,3}$, Antonio D. Ligsay ${ }^{4,5}$, and Emmanuel S. Baja ${ }^{1,2, *}$, \\ ${ }^{1}$ Department of Clinical Epidemiology, College of Medicine, University of the Philippines-Manila, City of \\ Manila, Philippines; email: zgregencia@up.edu.ph; gvdalmacion1@up.edu.ph \\ 2 Exposure Assessment, Epidemiology, and Risk Lab, Institute of Clinical Epidemiology, National Institutes of \\ Health, University of the Philippines-Manila, City of Manila, Philippines; email: esbaja@up.edu.ph \\ ${ }^{3}$ Professional Regulation Commission, P. Paredes, Nicanor Reyes St, Sampaloc, Manila, 1008 Metro Manila, \\ Philippines \\ ${ }^{4}$ The Graduate School \& College of Science, University of Santo Tomas, España Blvd., Manila 1008 Philippines; \\ email: adligsay@ust.edu.ph \\ ${ }^{5}$ Clinical Research Section, St. Luke's College of Medicine - William H. Quasha Memorial, 279 E. Rodriguez Sr. \\ Ave, Quezon City, 1112 Philippines \\ *Correspondence: esbaja@up.edu.ph
}

\begin{abstract}
Exposure to traffic-related air pollution is linked with acute alterations in blood pressure (BP). We examined the cumulative short-term effect of black carbon (BC) exposure on systolic (SBP) and diastolic (DBP) BP and assessed effect modification by participant characteristics. SBP and DBP were repeatedly measured on 152 traffic enforcers. Using a linear mixed-effects model with random intercepts, quadratic (QCDL) and cubic (CCDL) constrained distributed lag models were fitted to estimate the cumulative effect of BC concentration on SBP and DBP during the 10-hours (daily exposure) and 7-days (weekly exposure) before the BP measurement. Ambient BC was related to increased BP with QCDL models. An interquartile range change in BC cumulative during the 7 -days before the BP measurement was associated with increased BP [1.2\% change in mean SBP, $95 \%$ confidence interval (CI), 0.1 to 2.3 ; and $0.5 \%$ change in mean DBP, $95 \% \mathrm{CI},-0.8$ to 1.7$]$. Moreover, the association between the 10-hours cumulative BC exposure and SBP was stronger for females $(4.0 \%$ change, $95 \%$ CI: $2.1-5.9)$ versus males and for obese (2.9\% change, $95 \%$ CI: $1.0-4.8)$ vs. non-obese traffic enforcers. Short-term cumulative exposure to ambient traffic-related BC could bring about cardiovascular diseases through mechanisms involving increased BP.
\end{abstract}

Keywords: black carbon, diastolic blood pressure, MMDA traffic enforcers, obesity, sex, systolic blood pressure

\section{Introduction}

It is estimated that about 4.2 million people yearly across the world die from air pollution, according to the World Health Organization (WHO), and over 90\% of people breathe air containing high levels of pollutants [1,2]. Exposure reduction to air pollution has an essential impact on global public health since the adverse health effects of air pollution are usually driven through their detrimental impact on cardiovascular health [3]. Counties are now confronting significant public health and climate crises brought about by air pollution, which prompted the WHO to update the existing guidelines on air pollution in September 2021. WHO provided more robust evidence to demonstrate how air pollution affects different aspects of health at even lower concentrations than previously known [4]. 
Black Carbon $(\mathrm{BC})$ is a measured component of fine particulate matter $\left(\mathrm{PM}_{2.5}\right)$ in the air [5]. BC usually exists in submicron particles from combustion-related sources, including transportation, fossil fuel burning, residential heating, and industry [6]. Numerous epidemiological studies have provided evidence that BC exposure is linked to detrimental health effects [5,7-9]. It was emphasized by various researches the potential role of $\mathrm{BC}$ in influencing the variability of toxicologically active components of $\mathrm{PM}_{2.5}$ [10,11]. BC in urban environments is often related to adverse respiratory and cardiovascular effects, including an increase in blood pressure (BP) [12], increased cases of asthma, and premature deaths [13]. Unsustainable urbanization and outdated environmental protection legislation, which resulted in severe degradation of urban air quality in terms of BC emission, exacerbate these problems in developing megacities in South-East Asia, Latin America, and Africa [14]. There remain regional differences in BC-related health effects described in some epidemiological researches that cannot be fully explained by geographical variations in ambient concentrations of BC [6].

Several studies concluded that exposure to BC is associated with cardiovascular effects $[6,15,16]$. Although the evidence linking BC to subclinical cardiovascular endpoints is more limited than that for $\mathrm{PM}_{2.5}, \mathrm{BC}$ is of interest from a health perspective because multiple studies report associations between combustion-related air pollution and health effects [17-20]. In addition, acute and chronic BC exposures contribute to cardiovascular morbidity and mortality [21,22]. Physiological events happen to mediate these cardiovascular effects, such as an altered autonomic function of the heart, changes in micro- and macrovascular reactivity, induction of systemic inflammation, endothelial dysfunction, and altered peripheral resistance of the blood vessels [23-26]. Moreover, elevation in BP and an increased risk for developing hypertension usually result from microcirculation, which determines the overall peripheral resistance and microvascular alterations [12]. One study in Beijing, China, demonstrated the impact of short-term variation in high levels of ambient air pollution metrics on health outcomes. Results showed that both $\mathrm{PM}_{2.5}$ and $\mathrm{BC}$ are linked to BP increase and insulin resistance, even among at-risk individuals who have been living for long periods in these conditions [27]. The study also demonstrated that personal exposure to BC elevates blood pressure and heart rate within a few hours [27].

In less developed and developing countries, megacities endure high levels of trafficrelated air pollution and its health effects due to rapid urbanization, modernization, and economic growth [13]. Metro Manila, Philippines, is one of those megacities and home to approximately 13 million people. The air quality situation in Metro Manila is frequently hazardous due to various sources of pollution, and the residents intermingle in condensed limited spaces [14]. Furthermore, Metro Manila is reported to have the highest number of registered motor vehicles compared with other cities in the Philippines. Based on the National Emissions Inventory by source conducted in 2015, the majority (65\%) of air pollutants in the Philippines came from mobile sources such as cars, motorcycles, diesel trucks, and buses. Moreover, almost $21 \%$ were contributed by stationary sources such as power plants and factories, and the rest (14\%) were from area sources such as construction activities and open burning of solid wastes. Conversely, Metro Manila inventory in the same year revealed that mobile sources contributed $88 \%$ to total air pollution in the area compared to $10 \%$ from stationary sources and a mere $2 \%$ from area sources [28].

There is a need to understand better the association between air pollution and health outcomes, including BC and BP levels. Our study examined the association between acute cumulative exposure to BC and BP, particularly systolic (SBP) and diastolic (DBP) BP, among urban traffic enforcers stationed along a major circumferential highway in Metro Manila. Moreover, we evaluated effect modification by the characteristics of the traffic enforcers. 


\section{Materials and Methods}

\subsection{Study Population and Study Site}

The study population involved 152 traffic enforcers who were actively employed and working for the Metropolitan Manila Development Authority (MMDA). Traffic enforcers stationed along the Epifanio de Los Santos Avenue (EDSA) were randomly selected from the list given by MMDA management. Recruitment was voluntary on the traffic enforcers and included 19-65 years old traffic enforcers working the 5:00 am to 2:00 pm shift from May 2014 to April 2015. In addition, traffic enforcers working on secondary roads and other highways, pregnant, and clinically diagnosed with pulmonary tuberculosis were excluded from the study. The study received ethics approval from an independent Ethics Review Committee.

\subsection{Data Collection}

\subsubsection{Health Assessment and Self-Administered Questionnaire}

As part of the baseline health assessment, weight and height measurements, and collection of serum samples, were done on all eligible traffic enforcers, including a self-administered questionnaire containing data on medical history, medication usage, alcohol consumption, smoking history, and other factors that could affect health. These measurements were done the day before the start of the workweek of the traffic enforcers. Furthermore, the traffic enforcers were asked to report four more visits to the MMDA command center clinic for additional BP measurements and blood extractions after their daily duty.

\subsubsection{Blood Pressure Measurement}

For the health outcome assessment, sitting SBP and DBP measurements of the traffic enforcers were recorded. The research team assessed the SBP and DBP of the traffic enforcers at the end of their scheduled duty at the MMDA command center clinic. Traffic enforcers were seated for $5 \mathrm{~min}$ with arms at the level of the heart before the SBP and DBP measurements. The average of three readings of SBP and DBP was used in the analysis. If the traffic enforcer was agitated, upset, or excited, an additional 10-15 min of sitting before the measurement of SBP and DBP was done. In addition, the participants were advised to avoid food, alcohol, caffeine, and tobacco for 30-60 min before measuring their SBP and DBP.

\subsubsection{Black Carbon and Meteorological Measurement}

Ambient $\mathrm{BC}$ levels were measured daily using a real-time, pocket-sized $\mathrm{BC}$ aerosol monitor (microAeth ${ }^{\circledR}$ Model AE51, AethLabs, Inc.). The monitor operated continuously for $24 \mathrm{hrs}$ and was positioned on the rooftop of the Metro Base Ver. 2.0 MMDA station command center at Orense Guadalupe, Makati, Philippines. For quality assurance of BC measurements, a second $\mathrm{BC}$ aerosol monitor was co-located at the rooftop site. Relative humidity (RH) and ambient temperature (AT) measurements were obtained from the Philippine Atmospheric, Geophysical, and Astronomical Services Administration - Department of Science and Technology (PAGASA-DOST) weather stations located in Science Garden, Quezon City. Moreover, the study had 570 valid BC exposure and BP outcome measurements of the 152 traffic enforcers who had one $(n=15)$, two $(n=23)$, three $(\mathrm{n}=25)$, four $(\mathrm{n}=11)$, or five $(\mathrm{n}=78)$ measurements. 


\subsection{Data Analysis}

Descriptive statistics and correlation coefficients were calculated to describe and evaluate the relationships among BC, SBP, DBP, and covariates. Associations between BC and the change in the mean of both systolic BP (SBP) and diastolic BP (DBP) were estimated using linear mixed-effects with random subject-specific intercepts regression models with an unstructured covariate matrix structure. It is a standard approach required to capture and account for the residual correlation among measurements within the same traffic enforcer and to take into account the heterogeneity in the traffic enforcer's overall BP measurements for the repeated measures data $[29,30]$.

Two BC-pollutant models were assessed. First, to examine the workday and 1-week exposure windows of traffic enforcers to BC, and to minimize multiple comparisons, the study fitted quadratic constrained distributed lag (QCDL), and cubic constrained distributed lag (CCDL), BC-pollutant models, to estimate the cumulative effect of BC during a 10-hour and a 7-day time window before the visit for the measurement of blood pressure [31]. The linear mixed-effects regression models for the cumulative effect of BC on BP take the general equation:

Quadratic Constrained Distributed Lag Linear Mixed-Effects Model (QCDL):

$$
\begin{aligned}
& E\left(Y_{i j}\right)=b_{0 i}+\beta_{0}+\alpha_{0}\left(\sum_{k=0}^{q} k^{0} B C_{i j-k}\right)+\alpha_{1}\left(\sum_{k=0}^{q} k^{1} B C_{i j-k}\right)+\alpha_{2}\left(\sum_{k=0}^{q} k^{2} B C_{i j-k}\right)+f\left(s_{i j}\right)+X_{i j}^{T} \beta \\
& E\left(Y_{i j}\right)=b_{0 i}+\beta_{0}+\alpha_{0} v_{0 i j}+\alpha_{1} v_{1 i j}+\alpha_{2} v_{2 i j}+f\left(s_{i j}\right)+X_{i j}^{T} \beta
\end{aligned}
$$

Cubic Constrained Distributed Lag Linear Mixed-Effects Model (CCDL):

$$
\begin{aligned}
& E\left(Y_{i j}\right)=b_{0 i}+\beta_{0}+\alpha_{0}\left(\sum_{k=0}^{q} k^{0} B C_{i j-k}\right)+\alpha_{1}\left(\sum_{k=0}^{q} k^{1} B C_{i j-k}\right)+\alpha_{2}\left(\sum_{k=0}^{q} k^{2} B C_{i j-k}\right)+\alpha_{2}\left(\sum_{k=0}^{q} k^{3} B C_{i j-k}\right)+f\left(s_{i j}\right)+X_{i j}^{T} \beta \\
& E\left(Y_{i j}\right)=b_{0 i}+\beta_{0}+\alpha_{0} v_{0 i j}+\alpha_{1} v_{1 i j}+\alpha_{2} v_{2 i j}+\alpha_{3} v_{3 i j}+f\left(s_{i j}\right)+X_{i j}^{T} \beta
\end{aligned}
$$

where $Y_{i j}$ is the BP (SBP or DBP) measurement of traffic enforcer $i$ at time $j, b_{o}$ is the overall intercept, $b_{o i}$ is the random intercept for traffic enforcer $i, v_{m i j}$ is a linear combination of the current and lagged values of $B C$ pollution $B C_{i j}\left(q=1\right.$ to 10 hours, or $q=1$ to 7 days), $f\left(s_{i j}\right)$ is the smooth function of calendar date (natural spline with 4 degrees of freedom), and $X_{1 i j, \ldots,} X_{r i j}$ are the parametric fixed effects covariate terms from 1 to $r$ identified a priori and measured at each visit in which the SBP and DBP measurements were taken. Based on the established relationship between BP and BC [32], the following covariates were controlled a priori in all the models: age, sex, body mass index (BMI), fasting blood glucose level, cholesterol level, hypertensive status (yes, no), cigarette smoking status (never, ever), alcohol drinking status (never, ever), years of work experience. [33-35]. In addition, we included the graduate of a 4-year degree (Yes/No) variable in the model to control for the socioeconomic status. Furthermore, we used a natural spline of calendar date with 4 degrees of freedom in the model to account for the variation in season and other possible long-term time trends in blood pressure. Moreover, we also modeled traffic enforcer's duty post effects with indicator variables and controlled 1-hour mean relative humidity and temperature using linear terms. The Akaike Information Criterion was used to determine the best model fit for the cumulative effect of BC on BP. 
For effect modification by participant characteristics, traffic enforcers were classified into two groups according to the following characteristics: sex (male; female), obesity status (obese, $\mathrm{BMI} \geq 30 \mathrm{~kg} / \mathrm{m}^{2}$; non-obese, $\mathrm{BMI}<30 \mathrm{~kg} / \mathrm{m}^{2}$ ), smoking status (ever smoker, never smoker), and drinking status (ever drinker, never drinker). Interaction terms between BC and the dichotomized effect modifier were included in the models. We reported the effect size estimates with a $95 \%$ confidence interval $(95 \% \mathrm{Cl})$ as percent change in mean BP (SBP or DBP) per interquartile range (IQR) change of BC. R Studio (Version 1.1.463 - (C) 20092018 RStudio, Inc.) was used in the analyses.

\section{Results}

\subsection{Demographic Profile and Health Assessment}

Five hundred seventy valid BP and BC measurements available for analysis were collected from 152 eligible MMDA traffic enforcer participants. The traffic enforcers were middle-aged men with a mean age $( \pm$ SD) of 37.2 years \pm 8.7 years who were generally slightly overweight with a mean BMI $\left( \pm\right.$ SD) of $25.9 \pm 4.2 \mathrm{~kg} / \mathrm{m}^{2}$. In addition, approximately 3 out of 4 traffic enforcers were drinkers, and 3 out of 20 were hypertensive. The mean SBP of the traffic enforcers was slightly elevated $(128.2 \mathrm{mmHg} \pm 16.2 \mathrm{SD})$ than the standard average SBP of $120.0 \mathrm{mmHg}$, while the mean DBP of the traffic enforcers was less than $(78.1 \mathrm{mmHg} \pm 11.1 \mathrm{SD})$ the acceptable normal DBP of $80 \mathrm{mmHg}$. Table 1 shows the other characteristics of the study participants.

Table 1. Characteristics of the study population $(\mathrm{N}=152)$.

\begin{tabular}{lc}
\multicolumn{1}{c}{ Characteristics } & Mean \pm SD, \% \\
\hline Age, years & $37.2 \pm 8.7$ \\
Male & 90.1 \\
Cholesterol level, $\mathrm{mg} / \mathrm{dL}$ & $203.5 \pm 38.4$ \\
Glucose fasting, $\mathrm{mg} / \mathrm{dL}$ & $102.6 \pm 47.5$ \\
Body mass index, $\mathrm{kg} / \mathrm{m}^{2}$ & $25.9 \pm 4.2$ \\
Obese (BMl $\geq 30 \mathrm{~kg} / \mathrm{m}^{2}$ ) & 16.4 \\
Hypertensive & 15.8 \\
Ever cigarette smoker & 44.1 \\
Ever drinker & 76.3 \\
College graduate & 36.2 \\
Work experience, years & $9.7 \pm 8.6$ \\
Systolic blood pressure, $\mathrm{mmHg}$ & $128.2 \pm 16.2$ \\
Diastolic blood pressure, $\mathrm{mmHg}$ & $78.1 \pm 11.1$ \\
\hline
\end{tabular}

Table 2 summarizes the exposure and meteorological variable measurements, including descriptive statistics of ambient $\mathrm{BC}, \mathrm{AT}$, and $\mathrm{RH}$ measurements. Ambient $\mathrm{BC}$ mean concentrations during the current measurement (0-hr lag), 10-hour lag, and 7-day 
lag prior to health measurements were $10.6 \mu \mathrm{g} / \mathrm{m}^{3} \pm 10.4 \mathrm{SD}, 8.1 \mu \mathrm{g} / \mathrm{m}^{3} \pm 5.1 \mathrm{SD}$, and 9.3 $\mu \mathrm{g} / \mathrm{m}^{3} \pm 8.6 \mathrm{SD}$, respectively.

Table 2. Concentration of temperature, relative humidity, and black carbon during (0-hr), 10-hr, or 7-d before blood pressure monitoring.

\begin{tabular}{lcccc}
\hline \multicolumn{1}{c}{ Variable } & Lag & Mean \pm SD & Median & IQR \\
\hline Black Carbon, $\mu \mathrm{g} / \mathrm{m}^{3}$ & $0-\mathrm{hr}$ & $10.6 \pm 10.4$ & 6.1 & 10.8 \\
& & & & \\
& $10-\mathrm{hr}$ & $8.1 \pm 5.1$ & 7.3 & 7.1 \\
& $7-\mathrm{d}$ & $9.3 \pm 8.6$ & 5.8 & 8.5 \\
Temperature, ${ }^{\circ} \mathrm{C}^{\mathrm{a}}$ & & $32.0 \pm 2.6$ & 32.1 & 3.4 \\
Relative humidity, \% & & $55.8 \pm 11.7$ & 54.4 & 15.7 \\
\hline
\end{tabular}

${ }^{a}$ Current 1 -hr mean temperature; ${ }^{b}$ Current 1 -hr mean relative humidity

\subsection{Effect of Black Carbon on Blood Pressure}

Fig. 1 compares the estimates for the cumulative BC exposure for both the 10-hr and the 7-day time window lag models. The results from both QCDL and CCDL models produced almost similar adjusted effect estimates and 95\% confidence intervals, with QCDL models exhibiting better Akaike Information Criterion model fit than the CCDL models. In the QCDL model, ambient BC was positively associated with both SBP and DBP for the 7-days cumulative exposure before the BP measurement [SBP: 1.2 percent change in mean SBP per IQR increase in cumulative BC exposure; $95 \%$ confidence interval (CI), 0.1 to 2.3; DBP: $0.5 \%$ change in mean DBP per IQR increase in cumulative BC exposure; $95 \% \mathrm{CI}$, 0.8 to $1.7 ;$ ]. In contrast, for the 10-hours cumulative exposure, we found null associations between ambient $\mathrm{BC}$ and blood pressure (SBP: $-0.4 \%$ change in mean SBP per IQR increase in cumulative BC exposure; $95 \% \mathrm{CI},-1.1$ to 0.3 ; DBP: $-0.6 \%$ change in mean DBP per $10 \%$ increase in cumulative $\mathrm{BC}$ exposure; $95 \% \mathrm{CI},-1.4$ to 0.2 , see Table S1 for more details).

Fig. 2 compares the pollutant model plots for the 10-hr and 7-day cumulative BC exposure time windows using QCDL and CCDL with hourly and daily lags. In addition, we found wider confidence intervals in the 7-day exposure time window as compared with the 10-hr exposure time window for both the QCDL and CCDL models. 


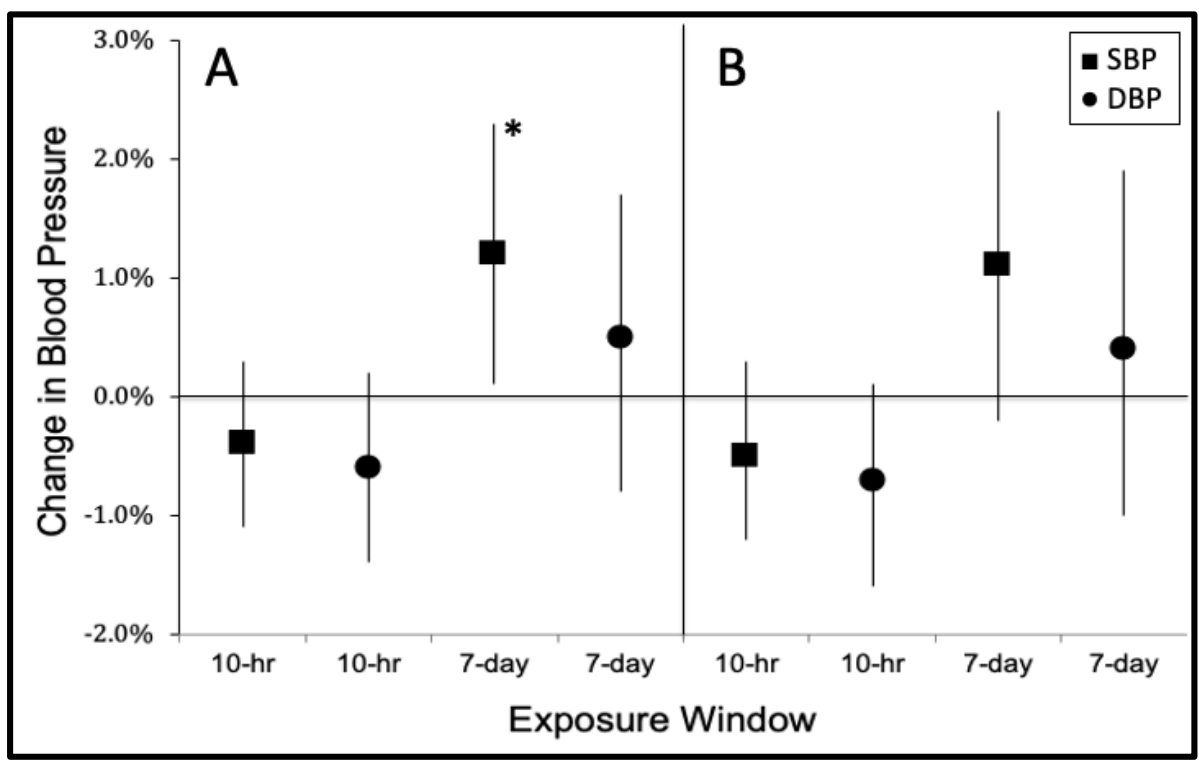

FIGURE 1. Adjusted effect estimates of percent change in systolic (SBP) and diastolic (DBP) blood pressure per interquartile range (IQR) change in cumulative exposure to black carbon during the 10 hours and 7 days before SBP and DBP measurements: pollutant model with random intercept using quadratic constrained distributed lags (A) and cubic constrained distributed lags (B). All models were adjusted for age; sex; body mass index; fasting blood glucose level; cholesterol level; hypertension status (yes, no); cigarette smoking status (never, ever); alcohol drinking status (never, ever); traffic enforcer's duty post; work experience; graduate of a 4-year degree (yes, no); temperature; relative humidity; and a natural spline for long-term time trend (date). Error bars indicate 95\% CI.

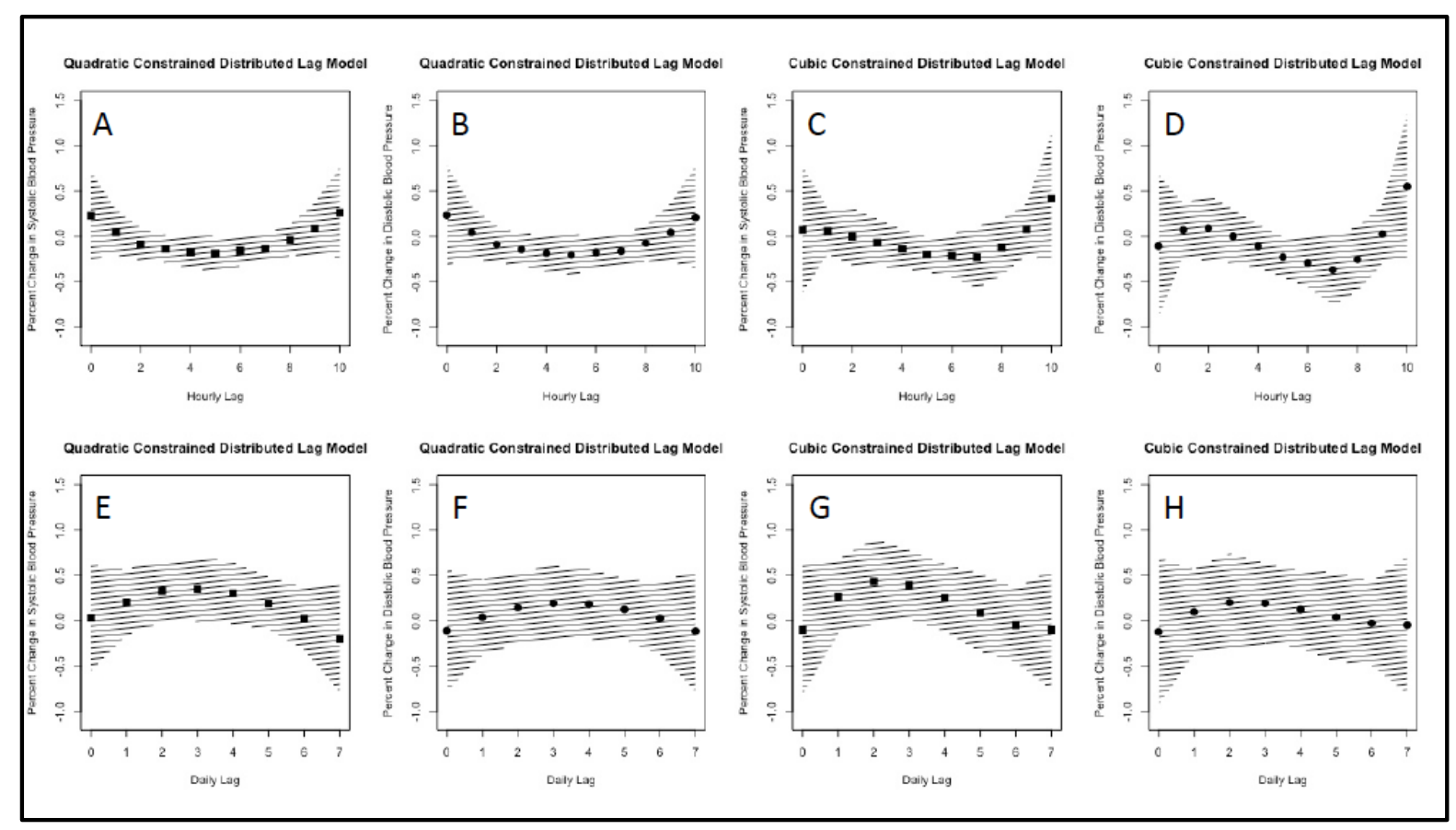

FIGURE 2. Adjusted effect estimates of percent change in systolic (SBP) and diastolic (DBP) blood pressure per interquartile range (IQR) change of traffic-related black carbon. (A-D) Pollutant model of cumulative exposure for a 10hr time window with random intercept using quadratic constrained distributed lag (QCDL) with hourly lags [SBP (A), and DBP (B)] and cubic constrained distributed lag (CCDL) with hourly lags [SBP (C), and DBP (D)]. (E-H) Pollutant model of cumulative exposure for a 7-day time window with random intercept using QCDL with daily lags [SBP (E), and DBP (F)] and $C C D L$ with daily lags $[S B P(G)$, and DBP $(H)$ ]. Hatch-marked regions indicate $95 \% \mathrm{Cl}$. 


\subsection{Effect Modification by Participant Characteristics}

We assessed whether being a drinker, obese, smoker, or male or female modified the effect of BC on SBP and DBP. Fig. 3 shows the results of effect modification by participant characteristics for the QCDL model for the cumulative BC exposure during the 10-hours before BP measurement. BC was positively associated with SBP with a $4.0 \%$ (95\% CI: 2.1 to 5.9) change in mean SBP among female traffic enforcers but was negatively associated ( $-0.8 \%$ change; $95 \% \mathrm{CI}:-1.5$ to 0.0$)$ for male traffic enforcers. In addition, the association between BC and SBP was also stronger for obese (2.9\% change, $95 \%$ CI: 1.0 to 4.8 ) versus non-obese ( $-0.8 \%$ change, $95 \% \mathrm{CI}$ : -1.5 to 0.0$)$ traffic enforcers. No effect modification by smoking and drinking was observed for the effect of BC on both SBP and DBP (see Table S2 for more details).

Fig. 4 shows the results of effect modification by sex, obesity, drinking, and smoking status for the cumulative $\mathrm{BC}$ exposure during the 7-days before $\mathrm{BP}$ measurement using QCDL models. The association between the BC and SBP was more robust among females (3.3\% change, $95 \%$ CI: 0.4 to 6.3 ) than males ( $0.9 \%$ change, $95 \%$ CI: -0.2 to 2.1 ), and never drinking ( $2.4 \%$ change, $95 \% 0.5$ to 4.4 ) versus ever drinking (1.1\% change, $95 \%$ CI: -0.1 to 2.4) traffic enforcers (Table S3 for more details).

\section{Discussion}

Our study provides a significant suggestion that acute cumulative exposure for seven days to traffic-related BC is associated with increased SBP, a risk factor for stroke and heart attack. In contrast, null associations were found between BC and both SBP and DBP for a 10-hr cumulative exposure window. Moreover, results from our study also suggest that females, obese, and hypertensive traffic enforcers remain predominantly at risk from traffic-related BC exposure.

As a by-product of the incomplete combustion of fossil fuels, $\mathrm{BC}$ is among the prevalent ambient particles in the world. Exposure to traffic-related BC has a well-documented association with numerous adverse health outcomes, and the association of BC with increased systemic BP is among the most extensively studied [36-38]. Research reported that the emission in Manila is dominated by ultrafine particles comprising about $90 \%$ of the total ambient air pollution. In addition, BC emission shared up to $70 \%$ of the calculated emission factors of particle number. This finding implies that the urban air in Manila comprises high concentrations of ultrafine particles and BC particles, which are highly toxic [39]. EDSA is considered the busiest highway in Metro Manila. According to MMDA data in 2013, 156,000 vehicles, including diesel buses, provincial and local, represent a large part of EDSA traffic. This observation results in low profitability, excessive BC air pollution levels, and mediocre consideration for passengers [40]. Furthermore, our findings suggest an acute 1-week cumulative effect of ambient BC exposure on SBP. The strong association between traffic enforcers and ambient $\mathrm{BC}$ implies that ambient $\mathrm{BC}$ effects are linked to background levels of traffic-related BC pollution in Metro Manila, particularly to traffic enforcers' occupational health-related exposure. 


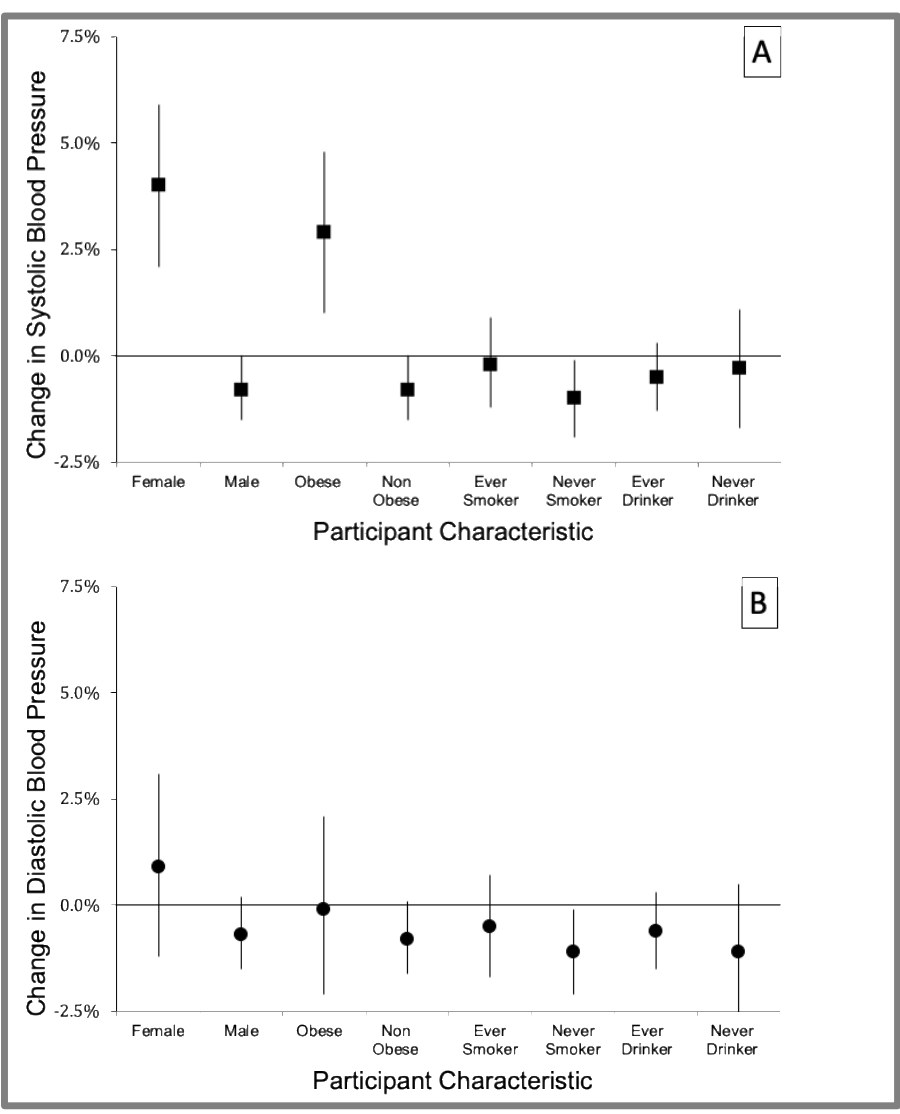

Figure 3. Adjusted change in mean systolic blood pressure per IQR change of traffic-related black carbon: cumulative exposure during 10-hours before blood pressure measurement, by participant characteristics [sex (male, female), obesity status (obese: body mass index $\geq 30$, non-obese: body mass index $<30$ ), smoking status (ever smoker, never smoker), and drinking status (ever drinker, never drinker)]. Error bars indicate 95\% CI.
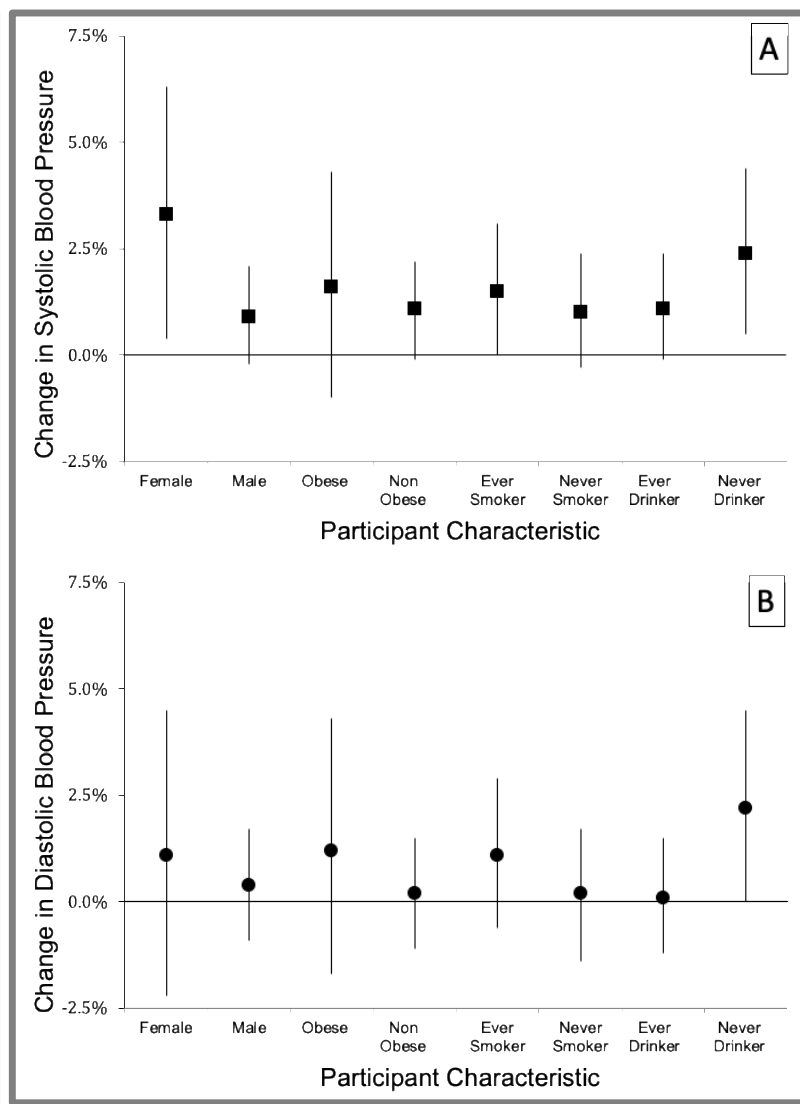

Figure 4. Adjusted change in mean systolic blood pressure per IQR change of traffic-related black carbon: cumulative exposure during 7-days before blood pressure measurement, by participant characteristics [sex (male, female), obesity status (obese: body mass index $\geq 30$, non-obese: body mass index $<30$ ), smoking status (ever smoker, never smoker), and drinking status (ever drinker, never drinker)]. Error bars indicate 95\% CI.

Our findings were consistently in agreement with previous studies that also examined the acute exposure effect of BC on BP [23,27,35,41-47]. For example, the 7-day cumulative exposure to ambient $B C$ and its positive effect on SBP and DBP findings from our study of traffic enforcers were supported by those from an aging cohort study of older men [23,35], a cohort of participants with metabolic syndrome [27], a panel study of subjects with Type 2 Diabetes Mellitus [43], and a study on hypertensive patients [47]. In addition, our results of null associations between a 10-hour cumulative exposure window to ambient BC and both SBP and DBP were comparable to a cross-over study of women [42] and a cohort of community dwellers living near major highways [41]. These studies showed null effects in SBP and DBP for a 3-hr [42] and 24-hr [41] prior exposure windows. However, some studies did not concur with our findings, including a controlled crossover study of healthy nonsmoking adults [44] and a non-smoking elderly cohort [46], which both studies reported positive associations on SBP and DBP.

Elevated BP has been considered worldwide as the most substantial modifiable risk factor for cardiovascular disease and related disability [48]. In 2016, air pollution was the fifth leading risk factor for the global burden of disease, with ambient $\mathrm{BC}$ pollution as the 
most important cause of illness among environmental risk factors. It led to 4.0 million deaths and 105.7 million disability-adjusted life years [49]. Elevated BP levels or less vasodilatation were found in humans experimentally exposed to concentrated ambient air pollution. [50]. Components of particles, especially ultrafine particles, induce oxidative stress responses [51], an important mechanism underlying hypertension [52].

Analysis of the effect modification by sex in our study indicated that the associations between the cumulative ambient BC exposure windows of 10-hrs and 7-days and elevated SBP were more robust for female than male traffic enforcers. Our findings did not agree with a cross-sectional study of police officers that reported men to have a significantly higher SBP than women in pre- and post-shift. The SBP of women was considerably higher post-shift than pre-shift [53]. Furthermore, males predominately have higher SBP than females in developing populations [54]. However, women may be more susceptible than men to the particulate matter-induced health effects; robust risk estimates have been reported for studies that found an increase in fatal coronary heart disease and cardiovascular events [55-57]. Our observed effect modification by sex needs to be verified in future studies.

Evidence of effect modification by obesity was observed on the association between 10 hours before BP measurement cumulative BC exposure and elevated SBP. In one study, obesity and blood pressure are associated; an increase in BMI is related to an increase in systolic blood pressure [58]. This study may support our finding of a stronger association between ambient BC and SBP among obese compared with non-obese traffic enforcers. Nonetheless, our results suggest that traffic enforcers who are female or obese may be more responsive to traffic-related ambient $\mathrm{BC}$ compared with traffic enforcers who are male or not obese.

Several studies have delved into exposure assessment and characterization of particulate matter, including black carbon in Metro Manila; however, the health effects of ambient black carbon exposure on susceptible populations in Metro Manila were never examined $[39,59,60]$. Similar to our health effects study of airborne heavy metals on BP [61], this study is the first study that looked at the association between acute ambient BC exposure and BP in the Philippines. Using a linear mixed model with random subject-specific intercept means that contrasts were both within and between subjects; therefore, bias due to confounding factors should be less than that observed in cross-sectional study design. However, bias as a result of unmeasured or residual confounding can never be disregarded.

Another limitation of our study is the BC exposure monitoring. We used a single site as a surrogate for acute ambient black carbon exposure that will not pick up the spatial variation in BC concentrations. With the traffic enforcers stationed $\sim 5 \mathrm{~km}$ on a median straight-line distance from our ambient monitoring site, adequate spatial variation in BC concentrations may be observed. Consequently, this spatial variation may lead to exposure misclassification that would likely be nondifferential and could bias our estimates toward the null [62]. Furthermore, our study utilized Filipino traffic enforcers as the study population who were young and predominantly healthy. Thus, the results of this study may not be generalizable to older people, children, or other ethnic and racial groups. 
Future studies on the health effect of ambient BC on BP on these at-risk populations should be considered.

\section{Conclusion}

Our study supports the health effects of elevated short-term cumulative exposure to ambient BC on increased SBP, a cardiovascular risk marker among urban traffic enforcers in Metro Manila, Philippines. In addition, male traffic enforcers appear to be better protected from SBP elevation with ambient BC exposure than female traffic enforcers. Moreover, when cumulatively exposed to ambient BC, even in shorter exposure windows, nonobese traffic enforcers tend to be protected against increased SBP compared with obese traffic enforcers. The findings of our study further suggest that short-term cumulative exposure to ambient BC could bring about cardiovascular diseases through mechanisms involving increased BP.

Supplementary Materials: The following are available online at www.mdpi.com/xxx/s1, Table S1: Adjusted effect estimates of percent change in systolic (SBP) and diastolic (DBP) blood pressure per interquartile range (IQR) change in cumulative exposure to black carbon during the 10 hours and 7 days before SBP and DBP measurements: pollutant model with random intercept using QCDL or CCDL. All models were adjusted for age; sex; BMI; cholesterol; hypertensive (yes, no); cigarette smoker (never, ever); alcohol drinker (yes, no); fasting blood glucose (FBG) level; years of service; graduate of a 4-year degree (yes, no); traffic enforcer's duty post; temperature; relative humidity; and a natural spline for long-term time trend (date, degrees of freedom =4), Table S2: Adjusted effect estimates of percent change in systolic (SBP) and diastolic (DBP) blood pressure per interquartile range (IQR) change in cumulative exposure to black carbon during the 10 hours before SBP and DBP measurements, by participant characteristics [sex (male, female), smoking (ever, never), obesity (obese $(+)$ : body mass index $\geq 30$, obese $(-)$ : body mass index $<30$ ), smoking status (ever smoker, never smoker), drinking status (drinker (+): yes, drinker (-): no), and hypertension status (hyper (+): yes, hyper (-): no)], and Table S3: Adjusted effect estimates of percent change in systolic (SBP) and diastolic (DBP) blood pressure per interquartile range (IQR) change in cumulative exposure to black carbon during the 7 days before SBP and DBP measurements, by participant characteristics [sex (male, female), smoking (ever, never), obesity (obese (+): body mass index $\geq 30$, obese (-): body mass index <30), smoking status (ever smoker, never smoker), drinking status (drinker $(+)$ : yes, drinker (-): no), and hypertension status (hyper (+): yes, hyper (-): no)].

Author Contributions: Conceptualization: ESB; Methodology and Data Collection: ESB; Formal Analysis \& Visualization: ESB Investigation: All authors; Resources: ESB, GVD, \& ADL; Data Curation: ESB \& ZGR; Writing - Original Draft Preparation: ESB \& ZGR; Writing - Review \& Editing: All authors;: Supervision \& Funding Acquisition: ESB.

Funding: The authors received a research grant (Grant \# FP-140002) from the Philippine Council for Health Research and Development (PCHRD) of the Department of Science and Technology (DOST), Philippines.

Institutional Review Board Statement: All procedures performed in studies involving human participants were in accordance with the ethical standards of the institutional research committee (Asian 
Eye Institute - Ethics Review Committee: ERC\# 2014-004) and with the 1964 Helsinki declaration and its later amendments or comparable ethical standards.

Informed Consent Statement: All participants provided their informed consent to participate in this study.

Data Availability Statement: The data are not publicly available due to privacy or ethical restrictions. Acknowledgement: The authors would like to thank the Philippine Council for Health Research and Development (PCHRD) of the Department of Science and Technology (DOST) for the funding the study, Former Chairman and now Senator Francis N. Tolentino, the Metropolitan Manila Development Authority management, Director Josie Faulan, Dr. Annabelle R. Ombina, and clinic staff for permitting and supporting the research team to conduct the study among their traffic enforcers, our research assistants, Don Paulo Guevarra, Billy Gorospe, Abby Quiroz, Dr. Abigail Santos, Dr. Ruby SoHao, and Nover Edward P. Duarte for making it easy for the study to collect the specimens and measurements needed by the study, and the volunteer traffic enforcers who participated in the study.

Conflicts of Interest: The authors declare no conflict of interest. The funders had no role in the design of the study; in the collection, analyses, or interpretation of data; in the writing of the manuscript, or in the decision to publish the results.

\section{References}

1. Stanaway, J.D.; Afshin, A.; Gakidou, E.; Lim, S.S.; Abate, D.; Abate, K.H.; Abbafati, C.; Abbasi, N.; Abbastabar, H.; AbdAllah, F. Global, regional, and national comparative risk assessment of 84 behavioural, environmental and occupational, and metabolic risks or clusters of risks for 195 countries and territories, 1990-2017: a systematic analysis for the Global Burden of Disease Study 2017. The Lancet 2018, 392, 1923-1994.

2. Organization, W.H. Air quality guidelines: global update 2005: particulate matter, ozone, nitrogen dioxide, and sulfur dioxide; World Health Organization: 2006.

3. Forouzanfar, M.H.; Afshin, A.; Alexander, L.T.; Anderson, H.R.; Bhutta, Z.A.; Biryukov, S.; Brauer, M.; Burnett, R.; Cercy, K.; Charlson, F.J. Global, regional, and national comparative risk assessment of 79 behavioural, environmental and occupational, and metabolic risks or clusters of risks, 1990-2015: a systematic analysis for the Global Burden of Disease Study 2015. The lancet 2016, 388, 1659-1724.

4. World Health, O. WHO global air quality guidelines: particulate matter (PM2.5 and PM10), ozone, nitrogen dioxide, sulfur dioxide and carbon monoxide; World Health Organization: Geneva, 2021.

5. $\quad$ EPA, U. Integrated science assessment for particulate matter. 2009.

6. Luben, T.J.; Nichols, J.L.; Dutton, S.J.; Kirrane, E.; Owens, E.O.; Datko-Williams, L.; Madden, M.; Sacks, J.D. A systematic review of cardiovascular emergency department visits, hospital admissions and mortality associated with ambient black carbon. Environment international 2017, 107, 154-162.

7. Rabito, F.A.; Yang, Q.; Zhang, H.; Werthmann, D.; Shankar, A.; Chillrud, S. The association between short - term residential black carbon concentration on blood pressure in a general population sample. Indoor air 2020, 30, 767-775.

8. Magalhaes, S.; Baumgartner, J.; Weichenthal, S. Impacts of exposure to black carbon, elemental carbon, and ultrafine particles from indoor and outdoor sources on blood pressure in adults: a review of epidemiological evidence. Environmental research 2018, 161, 345-353.

9. Segersson, D.; Eneroth, K.; Gidhagen, L.; Johansson, C.; Omstedt, G.; Nylén, A.E.; Forsberg, B. Health impact of PM10, PM2. 5 and black carbon exposure due to different source sectors in Stockholm, Gothenburg and Umea, Sweden. International journal of environmental research and public health $2017,14,742$. 
10. Bell, M.L.; Dominici, F.; Ebisu, K.; Zeger, S.L.; Samet, J.M. Spatial and temporal variation in PM2. 5 chemical composition in the United States for health effects studies. Environmental health perspectives 2007, 115, 989-995.

11. Janssen, N.A.; Hoek, G.; Simic-Lawson, M.; Fischer, P.; Van Bree, L.; Ten Brink, H.; Keuken, M.; Atkinson, R.W.; Anderson, H.R.; Brunekreef, B. Black carbon as an additional indicator of the adverse health effects of airborne particles compared with PM10 and PM2. 5. Environmental health perspectives 2011, 119, 1691-1699.

12. Louwies, T.; Nawrot, T.; Cox, B.; Dons, E.; Penders, J.; Provost, E.; Panis, L.I.; De Boever, P. Blood pressure changes in association with black carbon exposure in a panel of healthy adults are independent of retinal microcirculation. Environment international 2015, 75, 81-86.

13. Alas, H.D.; Müller, T.; Birmili, W.; Kecorius, S.; Cambaliza, M.O.; Simpas, J.B.B.; Cayetano, M.; Weinhold, K.; Vallar, E.; Galvez, M.C. Spatial characterization of black carbon mass concentration in the atmosphere of a Southeast Asian megacity: An air quality case study for Metro Manila, Philippines. Aerosol and Air Quality Research 2018, 18, 2301-2317+ ap2301.

14. Kecorius, S.; Madueño, L.; Vallar, E.; Alas, H.; Betito, G.; Birmili, W.; Cambaliza, M.O.; Catipay, G.; Gonzaga-Cayetano, M.; Galvez, M.C.; et al. Aerosol particle mixing state, refractory particle number size distributions and emission factors in a polluted urban environment: Case study of Metro Manila, Philippines. Atmospheric Environment 2017, 170, 169-183, doi:https://doi.org/10.1016/j.atmosenv.2017.09.037.

15. Kirrane, E.F.; Luben, T.; Benson, A.; Owens, E.; Sacks, J.; Dutton, S.; Madden, M.; Nichols, J. A systematic review of cardiovascular responses associated with ambient black carbon and fine particulate matter. Environment international 2019, 127, 305-316.

16. Biel, R.; Danieli, C.; Shekarrizfard, M.; Minet, L.; Abrahamowicz, M.; Baumgartner, J.; Liu, R.; Hatzopoulou, M.; Weichenthal, S. Acute cardiovascular health effects in a panel study of personal exposure to traffic-related air pollutants and noise in Toronto, Canada. Scientific reports 2020, 10, 1-12.

17. Kirrane, E.; Luben, T.; Benson, A.; Owens, E.; Sacks, J.; Dutton, S.; Madden, M.; Nichols, J. A systematic review of cardiovascular responses associated with ambient black carbon and fine particulate matter. Environment international 2019, 127, 305-316.

18. Baumgartner, J.; Zhang, Y.; Schauer, J.J.; Huang, W.; Wang, Y.; Ezzati, M. Highway proximity and black carbon from cookstoves as a risk factor for higher blood pressure in rural China. Proceedings of the National academy of sciences 2014, 111, 13229-13234.

19. Witters, K.; Dockx, Y.; Op't Roodt, J.; Lefebvre, W.; Vanpoucke, C.; Plusquin, M.; Vangronsveld, J.; Janssen, B.G.; Nawrot, T.S. Dynamics of skin microvascular blood flow in 4-6-year-old children in association with pre-and postnatal black carbon and particulate air pollution exposure. Environment International 2021, 157, 106799.

20. Lin, C.; Hu, D.; Jia, X.; Chen, J.; Deng, F.; Guo, X.; Heal, M.R.; Cowie, H.; Wilkinson, P.; Miller, M.R. The relationship between personal exposure and ambient PM2. 5 and black carbon in Beijing. Science of The Total Environment 2020, 737, 139801.

21. Yang, J.; Sakhvidi, M.J.Z.; de Hoogh, K.; Vienneau, D.; Siemiatyck, J.; Zins, M.; Goldberg, M.; Chen, J.; Lequy, E.; Jacquemin, B. Long-term exposure to black carbon and mortality: A 28-year follow-up of the GAZEL cohort. Environment International 2021, 157, 106805.

Tao, S.; Xu, Y.; Chen, M.; Zhang, H.; Huang, X.; Li, Z.; Pan, B.; Peng, R.; Zhu, Y.; Kan, H. Exposure to different fractions of diesel exhaust PM2. 5 induces different levels of pulmonary inflammation and acute phase response. Ecotoxicology and environmental safety 2021, 210, 111871.

23. Mordukhovich, I.; Wilker, E.; Suh, H.; Wright, R.; Sparrow, D.; Vokonas, P.S.; Schwartz, J. Black carbon exposure, oxidative stress genes, and blood pressure in a repeated-measures study. Environmental health perspectives 2009, 117, $1767-1772$.

24. Dubowsky, S.D.; Suh, H.; Schwartz, J.; Coull, B.A.; Gold, D.R. Diabetes, obesity, and hypertension may enhance associations between air pollution and markers of systemic inflammation. Environmental health perspectives 2006, 114, 992-998. 
25. Rückerl, R.; Ibald-Mulli, A.; Koenig, W.; Schneider, A. Air pollution and markers of inflammation and coagulation in patients with coronary heart disease. American journal of respiratory and critical care medicine 2006, 173, 432.

26. Park, S.K.; O’Neill, M.S.; Vokonas, P.S.; Sparrow, D.; Schwartz, J. Effects of air pollution on heart rate variability: the VA normative aging study. Environmental health perspectives 2005, 113, 304-309.

Brook, R.D.; Sun, Z.; Brook, J.R.; Zhao, X.; Ruan, Y.; Yan, J.; Mukherjee, B.; Rao, X.; Duan, F.; Sun, L. Extreme air pollution conditions adversely affect blood pressure and insulin resistance: the air pollution and cardiometabolic disease study. Hypertension 2016, 67, 77-85.

28. Environmental Management Bureau, E. Air Quality; Department of Environment and Natural Resources: Manila, Philippines, 2015.

29. Pearl, J. Causal diagrams for empirical research. Biometrika 1995, 82, 669-688.

30. Fitzmaurice, G.M.; Laird, N.M.; Ware, J.H. Applied longitudinal analysis; John Wiley \& Sons: $2012 ;$ Volume 998.

31. Baja, E.S.; Schwartz, J.D.; Wellenius, G.A.; Coull, B.A.; Zanobetti, A.; Vokonas, P.S.; Suh, H.H. Traffic-related air pollution and QT interval: modification by diabetes, obesity, and oxidative stress gene polymorphisms in the normative aging study. Environmental health perspectives 2010, 118, 840-846.

Brook, R.D.; Rajagopalan, S. Particulate matter, air pollution, and blood pressure. Journal of the American Society of Hypertension 2009, 3, 332-350.

33. Ding, N.; Wang, X.; Weisskopf, M.G.; Sparrow, D.; Schwartz, J.; Hu, H.; Park, S.K. Lead-related genetic loci, cumulative lead exposure and incident coronary heart disease: The normative aging study. PloS one 2016, 11.

34. Rapisarda, V.; Ledda, C.; Ferrante, M.; Fiore, M.; Cocuzza, S.; Bracci, M.; Fenga, C. Blood pressure and occupational exposure to noise and lead $(\mathrm{Pb})$ A cross-sectional study. Toxicology and industrial health 2016, 32, 1729-1736.

35. Wilker, E.H.; Baccarelli, A.; Suh, H.; Vokonas, P.; Wright, R.O.; Schwartz, J. Black carbon exposures, blood pressure, and interactions with single nucleotide polymorphisms in MicroRNA processing genes. Environmental health perspectives 2010, 118, 943-948.

36. Nwanaji-Enwerem, J.C.; Wang, W.; Nwanaji-Enwerem, O.; Vokonas, P.; Baccarelli, A.; Weisskopf, M.; Herndon, L.W.; Wiggs, J.L.; Park, S.K.; Schwartz, J. Association of Long-term Ambient Black Carbon Exposure and Oxidative Stress Allelic Variants With Intraocular Pressure in Older Men. JAMA Ophthalmol 2019, 137, 129-137, doi:10.1001/jamaophthalmol.2018.5313.

37. Hudda, N.; Eliasziw, M.; Hersey, S.O.; Reisner, E.; Brook, R.D.; Zamore, W.; Durant, J.L.; Brugge, D. Effect of Reducing Ambient Traffic-Related Air Pollution on Blood Pressure: A Randomized Crossover Trial. Hypertension 2021, 77, 823-832.

38. Mann, J.K.; Lutzker, L.; Holm, S.M.; Margolis, H.G.; Neophytou, A.M.; Eisen, E.A.; Costello, S.; Tyner, T.; Holland, N.; Tindula, G. Traffic-related air pollution is associated with glucose dysregulation, blood pressure, and oxidative stress in children. Environmental Research 2021, 195, 110870.

39. Madueño, L.; Kecorius, S.; Birmili, W.; Müller, T.; Simpas, J.; Vallar, E.; Galvez, M.C.; Cayetano, M.; Wiedensohler, A. Aerosol Particle and Black Carbon Emission Factors of Vehicular Fleet in Manila, Philippines. Atmosphere 2019, 10, 603.

40. Boquet, Y. Battling congestion in Manila: the EDSA problem. Transport and Communications Bulletin for Asia and the Pacific 2013, 82, 45-69.

41. Chung, M.; Wang, D.D.; Rizzo, A.M.; Gachette, D.; Delnord, M.; Parambi, R.; Kang, C.-M.; Brugge, D. Association of PNC, BC, and PM2. 5 measured at a central monitoring site with blood pressure in a predominantly near highway population. International journal of environmental research and public health 2015, 12, 2765-2780.

42. Weichenthal, S.; Hatzopoulou, M.; Goldberg, M.S. Exposure to traffic-related air pollution during physical activity and acute changes in blood pressure, autonomic and micro-vascular function in women: a cross-over study. Particle and fibre toxicology 2014, 11, 70. 
43. Hoffmann, B.; Luttmann-Gibson, H.; Cohen, A.; Zanobetti, A.; de Souza, C.; Foley, C.; Suh, H.H.; Coull, B.A.; Schwartz, J.; Mittleman, M. Opposing effects of particle pollution, ozone, and ambient temperature on arterial blood pressure. Environmental health perspectives 2012, 120, 241-246.

44. Kubesch, N.; De Nazelle, A.; Guerra, S.; Westerdahl, D.; Martínez, D.; Bouso, L.; Carrasco-Turigas, G.; Hoffmann, B.; Nieuwenhuijsen, M. Arterial blood pressure responses to short-term exposure to low and high traffic-related air pollution with and without moderate physical activity. European Journal of Preventive Cardiology 2015, 22, 548-557.

45. Zhao, X.; Sun, Z.; Ruan, Y.; Yan, J.; Mukherjee, B.; Yang, F.; Duan, F.; Sun, L.; Liang, R.; Lian, H. Personal black carbon exposure influences ambulatory blood pressure: air pollution and cardiometabolic disease (AIRCMD-China) study. Hypertension 2014, 63, 871-877.

46. Liu, L.; Ruddy, T.; Dalipaj, M.; Poon, R.; Szyszkowicz, M.; You, H.; Dales, R.E.; Wheeler, A.J. Effects of indoor, outdoor, and personal exposure to particulate air pollution on cardiovascular physiology and systemic mediators in seniors. Journal of Occupational and Environmental Medicine 2009, 51, 1088-1098.

47. Lin, Z.; Wang, X.; Liu, F.; Yang, X.; Liu, Q.; Xing, X.; Cao, J.; Li, J.; Huang, K.; Yan, W. Impacts of Short-Term Fine Particulate Matter Exposure on Blood Pressure Were Modified by Control Status and Treatment in Hypertensive Patients. Hypertension 2021, HYPERTENSIONAHA. 120.16611.

48. Olsen, M.H.; Angell, S.Y.; Asma, S.; Boutouyrie, P.; Burger, D.; Chirinos, J.A.; Damasceno, A.; Delles, C.; Gimenez-Roqueplo, A.-P.; Hering, D. A call to action and a lifecourse strategy to address the global burden of raised blood pressure on current and future generations: the Lancet Commission on hypertension. The Lancet 2016, 388, 2665-2712.

49. Collaborators, G.R.F. Global, regional, and national comparative risk assessment of 79 behavioural, environmental and occupational, and metabolic risks or clusters of risks, 1990-2015: a systematic analysis for the Global Burden of Disease Study 2015. Lancet (London, England) 2016, 388, 1659.

50. Brook, R.D.; Urch, B.; Dvonch, J.T.; Bard, R.L.; Speck, M.; Keeler, G.; Morishita, M.; Marsik, F.J.; Kamal, A.S.; Kaciroti, N. Insights into the mechanisms and mediators of the effects of air pollution exposure on blood pressure and vascular function in healthy humans. Hypertension 2009, 54, 659-667.

51. Li, N.; Sioutas, C.; Cho, A.; Schmitz, D.; Misra, C.; Sempf, J.; Wang, M.; Oberley, T.; Froines, J.; Nel, A. Ultrafine particulate pollutants induce oxidative stress and mitochondrial damage. Environmental health perspectives 2003, 111, 455-460.

Rafee, L.; Abedini, M.; Javanmard, S.H.; Sarrafzadegan, N.; Mansourian, M. Association of GSTT1 and GSTM1 polymorphisms with blood pressure: A Bayesian modeling of continuous data. Journal of Research in Medical Sciences: The Official Journal of Isfahan University of Medical Sciences 2014, 19, 200.

53. Elliott, J.L.; Lal, S. Blood pressure, sleep quality and fatigue in shift working police officers: effects of a twelve hour roster system on cardiovascular and sleep health. International journal of environmental research and public health 2016, 13, 172.

54. Tesfaye, F.; Nawi, N.; Van Minh, H.; Byass, P.; Berhane, Y.; Bonita, R.; Wall, S. Association between body mass index and blood pressure across three populations in Africa and Asia. Journal of human hypertension 2007, 21, 28-37.

Hamanaka, R.B.; Mutlu, G.M. Particulate Matter Air Pollution: Effects on the Cardiovascular System. Front Endocrinol (Lausanne) 2018, 9, 680-680, doi:10.3389/fendo.2018.00680.

56. Miller, K.A.; Siscovick, D.S.; Sheppard, L.; Shepherd, K.; Sullivan, J.H.; Anderson, G.L.; Kaufman, J.D. Long-term exposure to air pollution and incidence of cardiovascular events in women. New England Journal of Medicine 2007, 356, 447-458.

Puett, R.C.; Hart, J.E.; Yanosky, J.D.; Paciorek, C.; Schwartz, J.; Suh, H.; Speizer, F.E.; Laden, F. Chronic fine and coarse particulate exposure, mortality, and coronary heart disease in the Nurses' Health Study. Environmental health perspectives 2009, 117, 1697-1701.

58. Linderman, G.C.; Lu, J.; Lu, Y.; Sun, X.; Xu, W.; Nasir, K.; Schulz, W.; Jiang, L.; Krumholz, H.M. Association of body mass index with blood pressure among 1.7 million Chinese adults. JAMA network open 2018, 1, e181271-e181271. 
59. Kecorius, S.; Madueño, L.; Vxallar, E.; Alas, H.; Betito, G.; Birmili, W.; Cambaliza, M.O.; Catipay, G.; Gonzaga-Cayetano, M.; Galvez, M.C. Aerosol particle mixing state, refractory particle number size distributions and emission factors in a polluted urban environment: Case study of Metro Manila, Philippines. Atmospheric environment 2017, 170, 169-183.

60. Bagtasa, G.; Chung-Shin, Y. Influence of local meteorology on the chemical characteristics of fine particulates in Metropolitan Manila in the Philippines. Atmospheric Pollution Research 2020.

61. Regencia, Z.J.G.; Dalmacion, G.V.; Quizon, D.B.; Quizon, K.B.; Duarte, N.E.P.; Baja, E.S. Airborne heavy metals and blood pressure: Modification by sex and obesity in the MMDA traffic enforcers' health study. Atmospheric Pollution Research 2020.

62. Sarnat, J.A.; Brown, K.W.; Schwartz, J.; Coull, B.A.; Koutrakis, P. Ambient gas concentrations and personal particulate matter exposures: implications for studying the health effects of particles. Epidemiology 2005, 385-395. 